\title{
Bridge Engineering
}

\section{Book review}

\section{Bridge Deck Erection Equipment - A Best Practice Guide by Members of IABSE Working Group 6}

S. Harridge and M. Meyer (eds). ICE Publishing, London, UK, 2018 ISBN 978-07-277619-3-4, f120, 460 pp.

The stated aim of this book is to provide a best practice guide on bridge deck erection equipment across the whole range of likely stakeholders, from clients to various designers, managers, contractors and subcontractors.

The book is written by ten different authors and a brief half-page pen portrait of each author is provided. Following the introductory chapter, there are 19 chapters by these authors, grouped into four broad categories: management and safety has three chapters, erection equipment has ten chapters (and is by far the largest section of the book), design aspects are covered in five chapters and the final section is just one chapter, on recommendations. The book is extensively illustrated with colour diagrams and photographs of current bridge deck erection equipment. Mike Schlaich provides a short forward to the book, highlighting the excitement raised by these impressive bridge-building machines. He also, however, notes that the book closes a gap which many, unfortunately, do not know exists: for such major bridges, no successful design is possible without bearing the construction process in mind.
I believe the idea for this book came from an IABSE conference in Singapore after a spate of gantry failures and near-misses in the 1990s and early 2000s. I attended the conference as I had been involved with such machines and was looking at the construction of the viaducts on the Second Penang Bridge, which used 120 m long gantries on its $17 \mathrm{~km}$ of viaducts. The book is primarily concerned with such concrete viaducts. There are some sections relevant to steel bridges and a section on cable-stayed bridge construction. It does not cover the machines used to build suspension bridges, but this is of no matter - what it does cover, it covers well.

Eight of the ten authors are European and so one criticism of the book might be that it concentrates on European, US and Australian methodology and misses the huge Asian and particularly Chinese perspective where methods may differ significantly from the European view.

Who should read this book? Well, for a student or graduate interested in major bridges, buy it and just look at the pictures - that alone will significantly increase your knowledge and understanding of the details needed. For engineers involved in the design of major bridges and viaducts, this book is a must-have. The distillation of knowledge of the ten experts means you will find things in here you did not know that you need to know!

David Collings 